\title{
INFLUENCE OF PRE-TREATMENT AND DRYING METHODS ON PROCESS OF REHYDRATION OF DRIED APPLE
}

\author{
Tomasz Hebda, Beata Brzychczyk, Boguslawa Lapczynska-Kordon, Jakub Styks \\ University of Agriculture in Krakow, Poland \\ tomasz.hebda@ur.krakow.pl, beata.brzychczyk@ur.krakow.pl, boguslawa.lapczynska- \\ kordon@urk.edu.pl,jakub.styks@urk.edu.pl
}

\begin{abstract}
Fruit and vegetable processing is a difficult problem in the food industry. The raw materials are characterized by limited durability, and at the same time may belong to highly different varieties and species, which is why their suitability for processing varies. The most important task of the agricultural and food industry is to secure harvests so that they can be consumed throughout the year. The factors that determine the quality of fresh and processed food are primarily the type and quality of the raw material, the type of pre-treatment and further processing, as well as the conditions under which the raw material and the finished product were stored. The scope of the paper includes: - preparation of raw material samples (slices), - pre-treatment (blanching in steam, soaking in a starch solution), - drying the raw material (dryer with air circulation, no air circulation), - rehydration of the dried material (cold and warm water, time: 150 minutes). On the basis of the conducted tests, it was found that in the case of patches, the largest mass after the rehydration process was shown by samples dried in an air dryer, blanched in steam and rehydrated in hot water. In comparison with the mass of the fresh raw material, the patch after rehydration returned in $85.5 \%$ to its initial state. The weakest effect on the mass gain of the dried slices results from pre-treatment in the starch solution, drying without air circulation, and then rehydration in cold water. None of the samples after 150 minutes of hydration reached the mass of the fresh raw material.
\end{abstract}

Keywords: rehydrated process, dried apple, pre-treatment.

\section{Introduction}

Drying is one of the most important processes of thermal food preservation. The purpose of drying is to reduce the water content to a level that prevents the development of enzymatic reactions and microorganisms that negatively affect the quality of the dried material. Most dehydrated products are rehydrated during their use (dry mixes and soups, dried fruits, etc.). On the basis of the research it was found that rehydration depends on the method and parameters of drying and previous pretreatment [1-4], and also damage to the internal structure of materials [5;6]. Rehydration of dried plant tissues consists of three simultaneous processes: absorption of water into the dried material, swelling and washing of soluble substances [7;8]. It is generally accepted that the degree of rehydration depends on the degree of cellular and structural damage. During drying, Jayaraman, Das Gupta and Babu Rao [9] observed irreversible breaks and dislocations of cells, resulting in the loss of integrity, and thus the dense structure of sunken, significantly shrunk capillaries, with reduced hydrophilic properties. The observed changes are the cause of the material inability to absorb sufficient water for full rehydration. Studies and rehydration of dried apple showed that the degree of rehydration depends on the method and parameters of drying, also on pre-treatment [1;2]. The measurements were carried out for selected varieties.

The aim of the paper was to analyze the mass changes and the relative mass gain of dried apple samples during rehydration.

\section{Materials and methods}

The Idared variety apples were tested. The material tested was prepared in the form of patches with a thickness of $3.0 \pm 0.1 \mathrm{~mm}$, the average diameter in the $d=70.0 \pm 5.0 \mathrm{~mm}$ range. All prepared samples were weighed on an analytical balance $( \pm 0.001 \mathrm{~g})$.

Before drying, these samples were subjected to the following pre-treatment processes:

1. blanching in steam - the material was placed on a sieve in a closed vessel with boiling water for $60 \mathrm{~s}$;

2. microwave heating - the heating took place in a $600 \mathrm{~W}$ microwave oven for $30 \mathrm{~s}$,

3. osmotic dehydration in a $10 \%$ starch solution $\left(\mathrm{C}_{6} \mathrm{H}_{10} \mathrm{O}_{5}\right)_{\mathrm{n}}(\text { molecular mass } 162.1)_{\mathrm{n}} \mathrm{g} \cdot \mathrm{mol}^{-1}$, at $20.0^{\circ} \mathrm{C}$, during $24 \mathrm{~h}$, at an osmotic pressure of the solution $\pi=1.5028 .103 \mathrm{hPa}$. The comparative material consisted of fresh apple samples that were not subjected to any pre-treatment. 
After the pre-treatment process, the material was re-weighed and subjected to a convection drying process at $70.0 \pm 5.0^{\circ} \mathrm{C}$. Drying was carried out until a stable mass was achieved. The convection drying process was carried out in two types of dryers: with forced air circulation (flow rate of the drying medium $1.5 \mathrm{~m} \cdot \mathrm{s}^{-1}$ ) and without forced air circulation. The raw material was laid in one layer on the shelves of the dryers. After the process was completed, mass measurements were carried out again.

Then, the rehydration process was carried out in water for two different temperature ranges:

- in distilled water at $20.0 \pm 0.1^{\circ} \mathrm{C}$;

- in distilled water at $95.0 \pm 5.0^{\circ} \mathrm{C}$.

The rehydration properties were determined by the relative mass gain. The kinetics of the rehydration process was investigated in $150 \mathrm{~min}$, with a step in time every 10 minutes. Samples were each drawn from water every 10 minutes, blotted and weighed.

A relative mass gain was determined from the dependence:

$$
\delta m=\frac{m\left(\tau_{i}\right)-m\left(\tau_{0}\right)}{m\left(\tau_{0}\right)}
$$

where $m\left(\tau_{i}\right)$ - mass at a given moment, $\mathrm{g}$;

$m\left(\tau_{0}\right)$ - initial mass, g.

\section{Results and discussion}

Studies have shown that the obtained samples, during hydration at ambient temperature, retain the similar character of curves, differing by the degree of mass gain of the rehydrate. The differences observed were analyzed in terms of the type of initial treatment of the first stage, the drying method and the method of rehydration, Figures $1 \mathrm{a}$ and $1 \mathrm{~b}$. The material obtained by convective drying, previously blanched or dried in the microwave, and the drought not subjected to any pre-treatment in the case of convection drying in a forced heat dryer, have similar values of the mass gain of the rehydrate than the same samples obtained in the dryer without circulation of the drying agent. On the other hand, dried apple, which was subjected in the first stage to osmotic drying in a $10 \%$ starch solution, is less prone to rehydration than other samples. The differences that can be seen in the rehydration of the above-mentioned samples concern the technology of obtaining dried stage II. On this basis, it was concluded that the pre-treatment method, with the exception of osmotic drying, of material dried convectionally with forced air circulation, has no significant effect on the weight gain of the rehydrated samples (rehydration process at $20.0 \pm 1.0^{\circ} \mathrm{C}$ ). The material obtained in the process of convection drying in a dryer without forced circulation and not subjected to any treatment of the first stage is, on average, in the first 45 minutes, about $5 \%$ less susceptible to the process of low temperature rehydration, and within the next 2 hours by about $16 \%$. The opposite was observed for samples subjected to the first stage treatments. The material blanched and dried in the convection dryer with circulation of the drying medium is on average $29 \%$ more susceptible to adsorption of water in the rehydration process than the drying obtained in the dryer without circulation. Drying in a forced flow dryer also increases the susceptibility to the rehydration of the raw material previously subjected to microwave drying by an average of $40 \%$. The greatest effect of the drying method, however, is visible in the case of the samples, which have been subjected to osmotic drying and then drying with the circulation of the medium. The average difference in mass increase in the sample irrigation process reaches $46 \%$.

In the case of the rehydration process carried out for the aforementioned samples at $95.0 \pm 5.0^{\circ} \mathrm{C}$, the highest mass gain over time is observed for blanched samples and then samples not subjected to any treatment, with the highest susceptibility occurring in samples dried in a forced circulation oven. For samples subjected to osmotic dehydration, the type of the second drying stage had no effect on the rehydration process at high temperature. The biggest differences can be seen in the case of samples dried in the microwave, Fig.1c and d. 

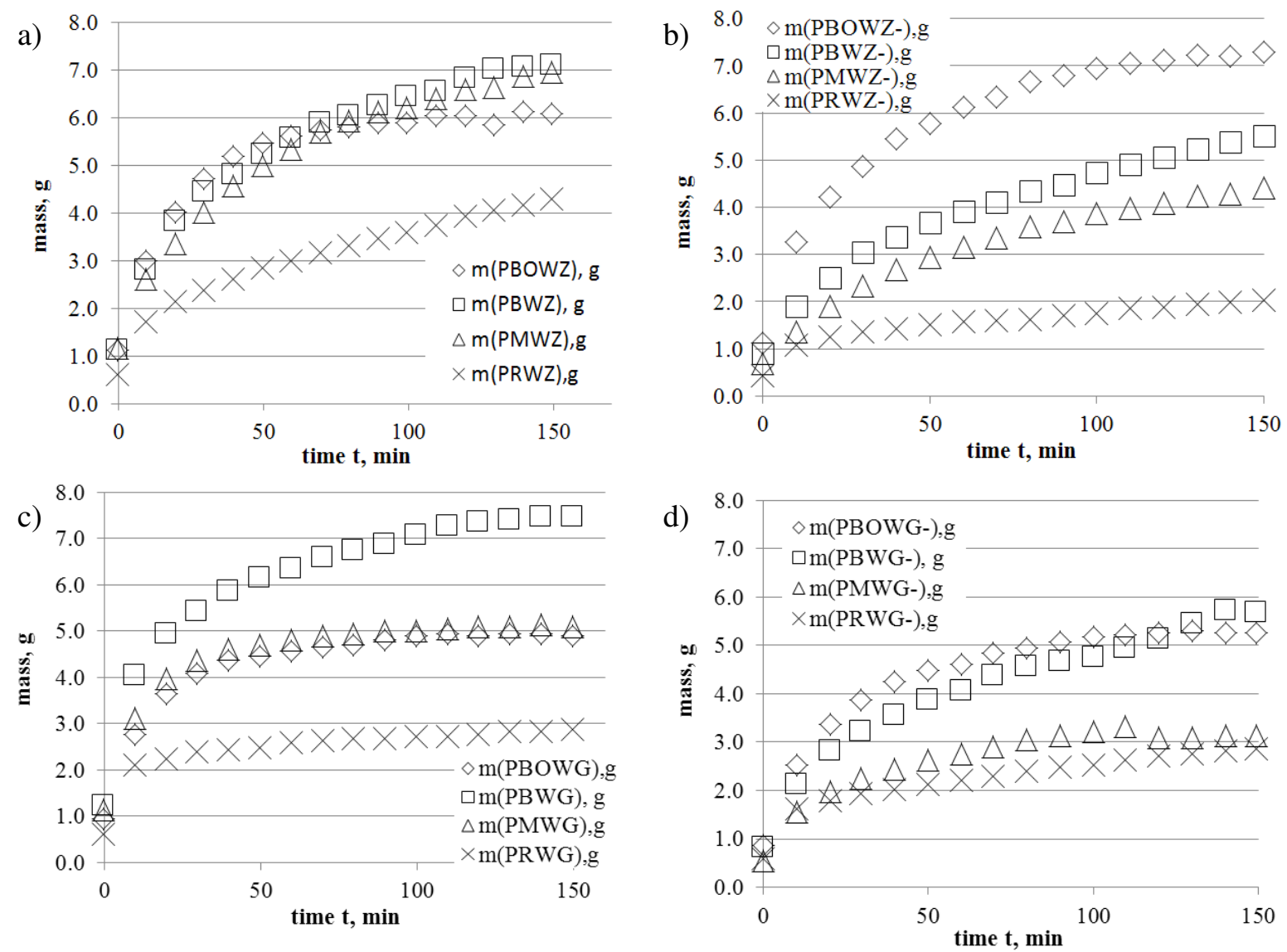

Fig. 1. Mass change of dried apples from Idared variety (slices), depending on type of pretreatment during rehydration: $\mathrm{a}$ - in distilled water at $20.0 \pm 1.0^{\circ} \mathrm{C}$ - dried in a convection dryer with circulation; $\mathrm{b}$ - in distilled water at a temperature of $20.0 \pm 1.0^{\circ} \mathrm{C}$ - material obtained in a convection oven without circulation; $\mathrm{c}$ - in distilled water at $95.0 \pm 5.0^{\circ} \mathrm{C}-$ dried in a circulating convection oven; $\mathrm{d}-$ in distilled water at $95.0 \pm 5.0^{\circ} \mathrm{C}$ - material obtained in a convection dryer without circulation. Source: own study. The legend:

dried sample with air circulation

$\mathrm{m}$ (PBOWZ) - mass of rehydrate - cold water without pre-treatment

m (PBWZ) - mass of rehydrate - cold water blanching,

m (PMWZ) - mass of rehydrate - cold water microwave drying,

m (PRWZ) - mass of rehydrate - cold water osmotic drying

m (PBOWG) - mass of rehydrate - hot water without pre-treatment,

m (PBWG) - mass of rehydrate - hot water blanching,

m (PMWG) - mass of rehydrate - hot water microwave drying,

m (PRWG) - mass of rehydrate - hot water osmotic drying dried samples without air circulation

m (PBOWZ-) - rehydrate mass - cold water -

without pre-treatment

m (PBWZ-) - mass of rehydrate - cold water blanching,

m (PMWZ-) - mass of rehydrate - cold water microwave drying,

m (PRWZ-) - mass of rehydrate - cold water osmotic drying

m (PBOWG-) - rehydrate mass - hot water without pre-treatment,

m (PBWG-) - mass of rehydrate - hot water blanching,

m (PMWG-) - mass of rehydrate - hot water microwave drying,

m (PRWG-) - mass of rehydrate - hot water osmotic drying

The raw material of these samples dried in an air convection oven was $42 \%$ more susceptible to mass gain than dried samples without air circulation. In the case of samples subjected to the process of blanching, the difference was as much as $33 \%$. The mass of samples dried osmotically and samples not subjected to the treatments of the first stage changed minimally. Samples rehydrated in hot water, which in the first stage were subjected to a microwave drying process and those that were not pre- 
treated, are from about 20-30\% less prone to the water adsorption process than samples blanched. Adsorption of water for samples that have not been subjected to the preceding osmotic dehydration process in a $10 \%$ glucose solution is on average $42.4 \%$ higher than for samples subjected to this procedure.

The diagrams contained in Figures 2a to 2d illustrate the effect of the drying and pre-treatment process on the degree of material hydration. Samples blanched and dried with air circulation underwent the highest degree of rehydration both low and high temperature compared to samples blanched and dried without air circulation, Fig. $2 b$. In the case of microwave drying, the temperature of the rehydration process had a smaller effect on the mass gain of the sample than the way in which the product was finally dried. Dried samples without air circulation were characterized by a lower degree of rehydration than dried ones with circulation, Fig. 2c. The least susceptible material for the rehydration process was the raw material subjected to the process of osmotic drying before the drying process, Fig. 2d. The samples obtained as a result of convection drying with the forced circulation of the drying agent underwent higher rehydration than samples obtained by convection drying without circulation. In the case of rehydration at $95.0 \pm 5.0^{\circ} \mathrm{C}$, the drying method had no effect on the mass gain of the dried material and the course of the curves was almost identical.


Fig. 2. Mass change of sample rehydrate depending on type pre-treatment and drying process: $\mathrm{a}$ - without pre-treatment; $\mathrm{b}$ - blanched; $\mathrm{c}$ - microwave drying; $\mathrm{d}$ - osmotic drying

The relative decrease in the apple mass growth during rehydration in distilled water, both at $20.0 \pm 1^{\circ} \mathrm{C}$ ambient temperature and $95.0 \pm 5.0^{\circ} \mathrm{C}$, as a function of time, depending on the type of pre-treatment of the raw material before the drying process, did not show separate character curves, Fig. 3. 

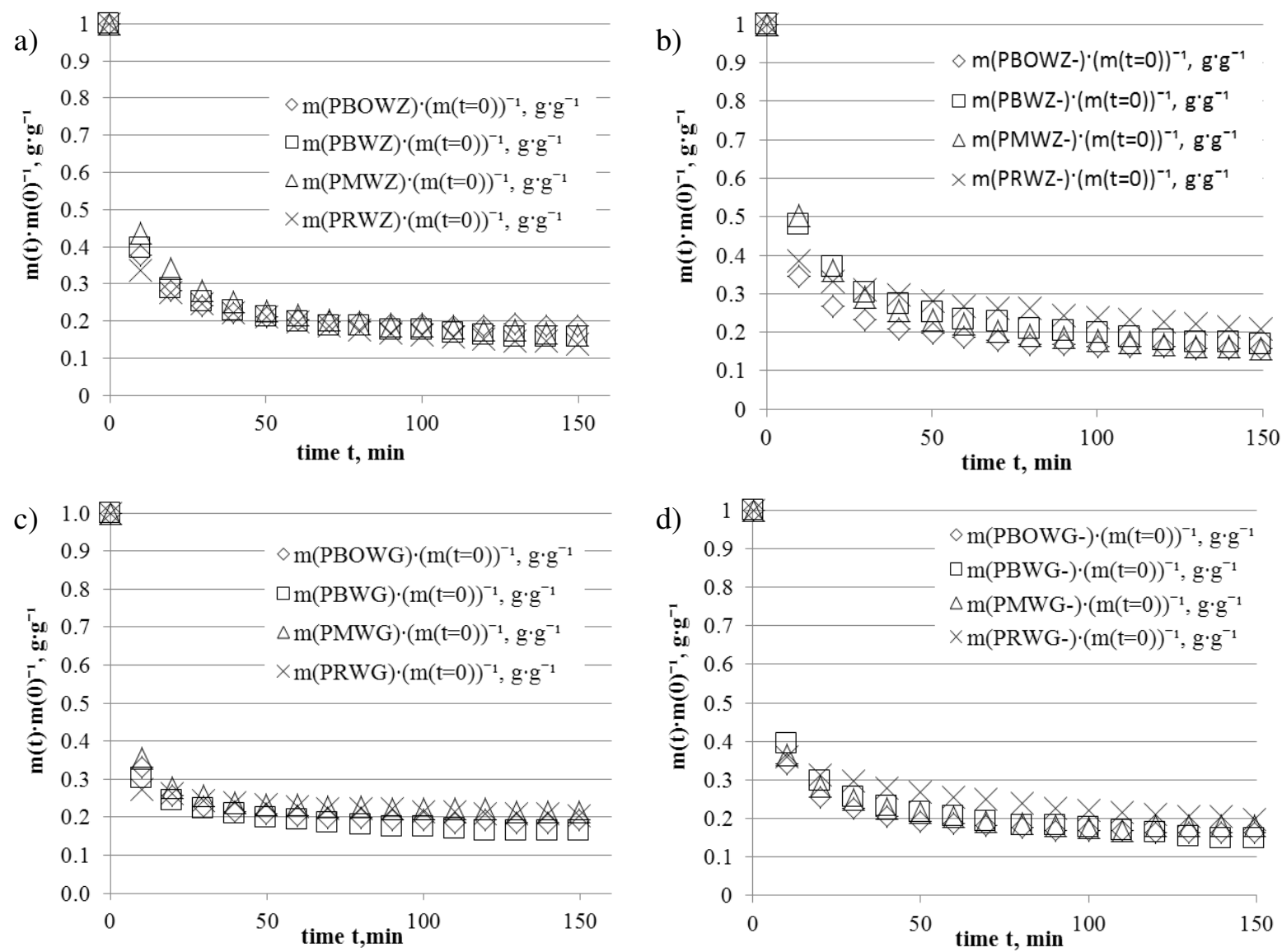

Fig. 3. Decrease of relative mass gain from dried Idared apple (slices): during rehydration: in distilled water at $20.0 \pm 1.0^{\circ} \mathrm{C}$ : a) material obtained in a convection dryer with circulation, b) material obtained in a convection dryer without circulation; during rehydration in distilled water at $95.0 \pm 5.0^{\circ} \mathrm{C}: \mathrm{c}$ ) material obtained in a convection dryer with circulation, d) material obtained in a convection-free convection oven. Source: own study. The legend:

dried sample with air circulation

$\mathrm{m} \quad(\mathrm{PBOWZ}) \cdot(\mathrm{m} \quad(\mathrm{t}=0))^{-1} \mathrm{~g} \cdot \mathrm{g}^{-1}-$ relative increase in rehydrate - cold water - without pretreatment,

$\mathrm{m}(\mathrm{PBWZ}) \cdot(\mathrm{m}(\mathrm{t}=0))^{-1} \mathrm{~g} \cdot \mathrm{g}^{-1}-$ relative increase in rehydrate - cold water - blanching,

$\mathrm{m}(\mathrm{PMWZ}) \cdot(\mathrm{m}(\mathrm{t}=0))^{-1} \mathrm{~g} \cdot \mathrm{g}^{-1}$ - relative increase in rehydrate - cold water - microwave drying,

$\mathrm{m}(\mathrm{PRWZ}) \cdot(\mathrm{m}(\mathrm{t}=0))^{-1} \mathrm{~g} \cdot \mathrm{g}^{-1}-$ relative increase in hydrate - cold water - osmotic drying.

$\mathrm{m} \quad(\mathrm{PBOWG}) \cdot(\mathrm{m} \quad(\mathrm{t}=0))^{-1} \mathrm{~g} \cdot \mathrm{g}^{-1}-$ relative increase in rehydrate - hot water - without pretreatment,

$\mathrm{m}(\mathrm{PBWG}) \cdot(\mathrm{m}(\mathrm{t}=0))^{-1} \mathrm{~g} \cdot \mathrm{g}^{-1}-$ relative increase in rehydrate - hot water - blanching,

$\mathrm{m}(\mathrm{PMWG}) \cdot(\mathrm{m}(\mathrm{t}=0))^{-1} \mathrm{~g} \cdot \mathrm{g}^{-1}-$ relative increase in rehydrate - hot water - microwave drying, $\mathrm{m}(\mathrm{PRWG}) \cdot(\mathrm{m}(\mathrm{t}=0))^{-1} \mathrm{~g} \cdot \mathrm{g}^{-1}-$ relative increase in rehydrate - hot water - drying osmotically dried samples without air circulation

$\mathrm{m} \quad(\mathrm{PBOWZ}-) \cdot(\mathrm{m} \quad(\mathrm{t}=0))^{-1} \mathrm{~g} \cdot \mathrm{g}^{-1}-$ relative increase in rehydrate - cold water - without pretreatment,

$\mathrm{m}(\mathrm{PBWZ}-) \cdot(\mathrm{m}(\mathrm{t}=0))^{-1} \mathrm{~g} \cdot \mathrm{g}^{-1}-$ relative increase in rehydrate - cold water - blanching,

$\mathrm{m} \quad(\mathrm{PMWZ}-) \cdot(\mathrm{m} \quad(\mathrm{t}=0))^{-1} \mathrm{~g} \cdot \mathrm{g}^{-1} \quad$ relative increase in rehydrate - cold water - microwave drying,

$\mathrm{m}(\mathrm{PRWZ}-) \cdot(\mathrm{m}(\mathrm{t}=0))^{-1} \mathrm{~g} \cdot \mathrm{g}^{-1}-$ relative increase in rehydrate - cold water - osmotic drying.

$\mathrm{m} \quad(\mathrm{PBOWG}-) \cdot(\mathrm{m} \quad(\mathrm{t}=0))^{-1} \mathrm{~g} \cdot \mathrm{g}^{-1}-$ relative increase in rehydrate - hot water - without pretreatment,

$\mathrm{m}($ PBWG- $) \cdot(\mathrm{m}(\mathrm{t}=0))^{-1} \mathrm{~g} \cdot \mathrm{g}^{-1}-$ relative increase in rehydrate - hot water - blanching,

$\mathrm{m} \quad(\mathrm{PMWG}-) \cdot(\mathrm{m} \quad(\mathrm{t}=0))^{-1} \mathrm{~g} \cdot \mathrm{g}^{-1} \quad$ relative increase in rehydrate - hot water - microwave drying,

$\mathrm{m}($ PRWG- $) \cdot(\mathrm{m}(\mathrm{t}=0))^{-1} \mathrm{~g} \cdot \mathrm{g}^{-1}-$ relative increase in rehydrate - hot water - drying osmotically 
The impact of the first stage pre-treatment treatments has no effect on the relative decrease in the mass gain of the dried material. After about 45 minutes in all cases, the relative decrease in the mass gain of the rehydration process of dried apple is stabilized as a function of time, regardless of what the previous type of pre-treatment was. The only slight differences are observed in the group of samples subjected to convective drying without the circulation of the drying medium, Fig. $3 \mathrm{~b}$ and $\mathrm{d}$.

The material of samples without pre-treatment, dried in the dryer without air circulation, in the water irrigation process is characterized in the first 45 minutes by a greater decrease in the relative mass gain similar to the samples blanched and dried osmotically, Fig. 4a, b and d. Rehydration in hot water in the case of untreated samples removes differences and the decrease in relative mass gain is identical, Fig. 4a. Fig. 4c.

The most even slope values are observed for samples dried by means of microwave radiation,
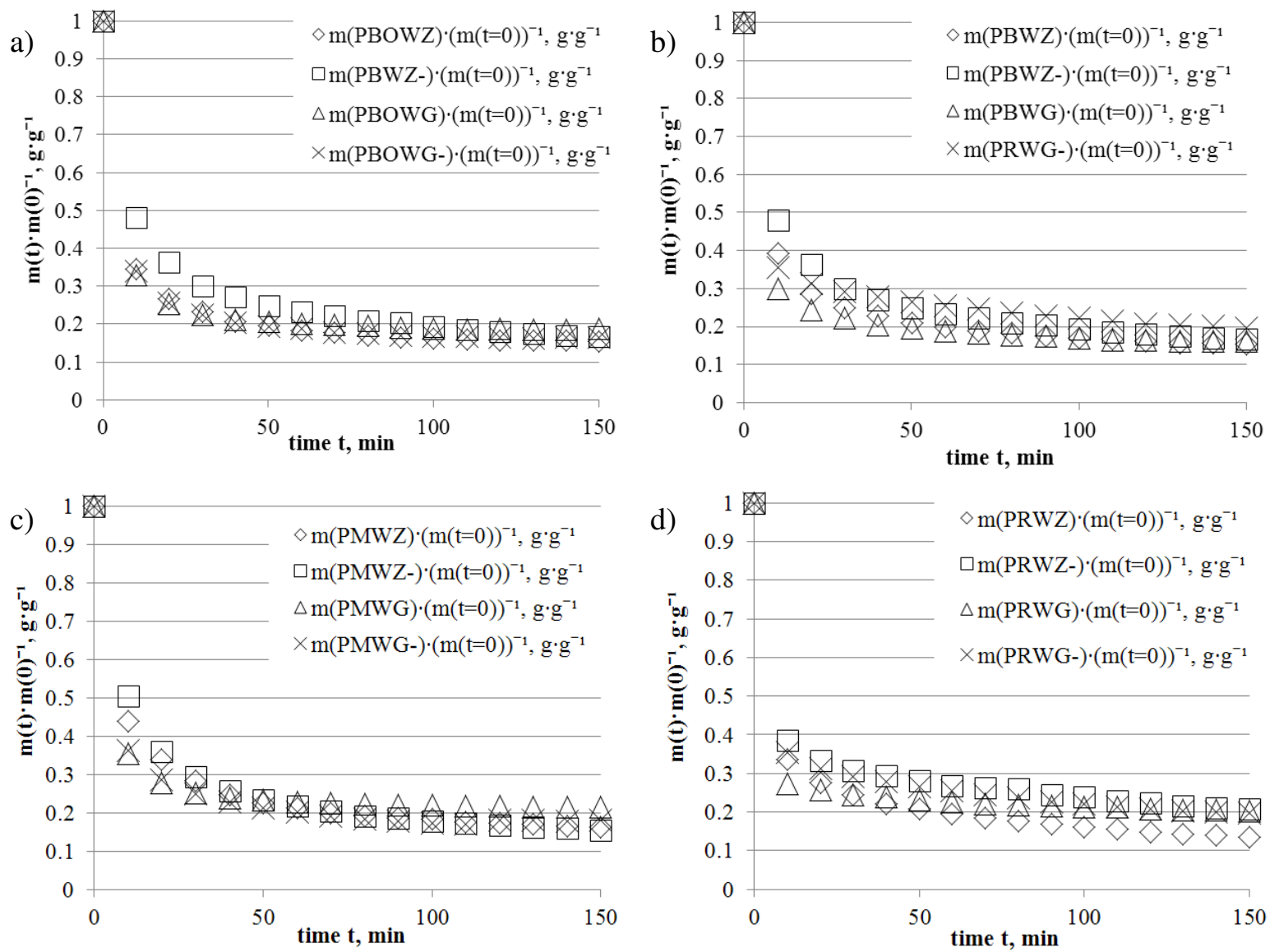

Fig. 4. Decrease of relative mass gain from dried Idared apple (slices) during rehydration depending on temperature of rehydration and drying process: a - without pre-treatment; $\mathrm{b}$ - blanched; c - microwave drying; $\mathrm{d}$ - osmotic drying. Source: own study.

The stabilization of the relative mass increase of dried apple for samples dried with forced air circulation occurs on average after about 50 minutes, Fig. 5 a and c. However, the stabilization of dried samples without air circulation, regardless of the type of pre-treatment, takes place after approx. 70 minutes, Fig. 5 b and d. 

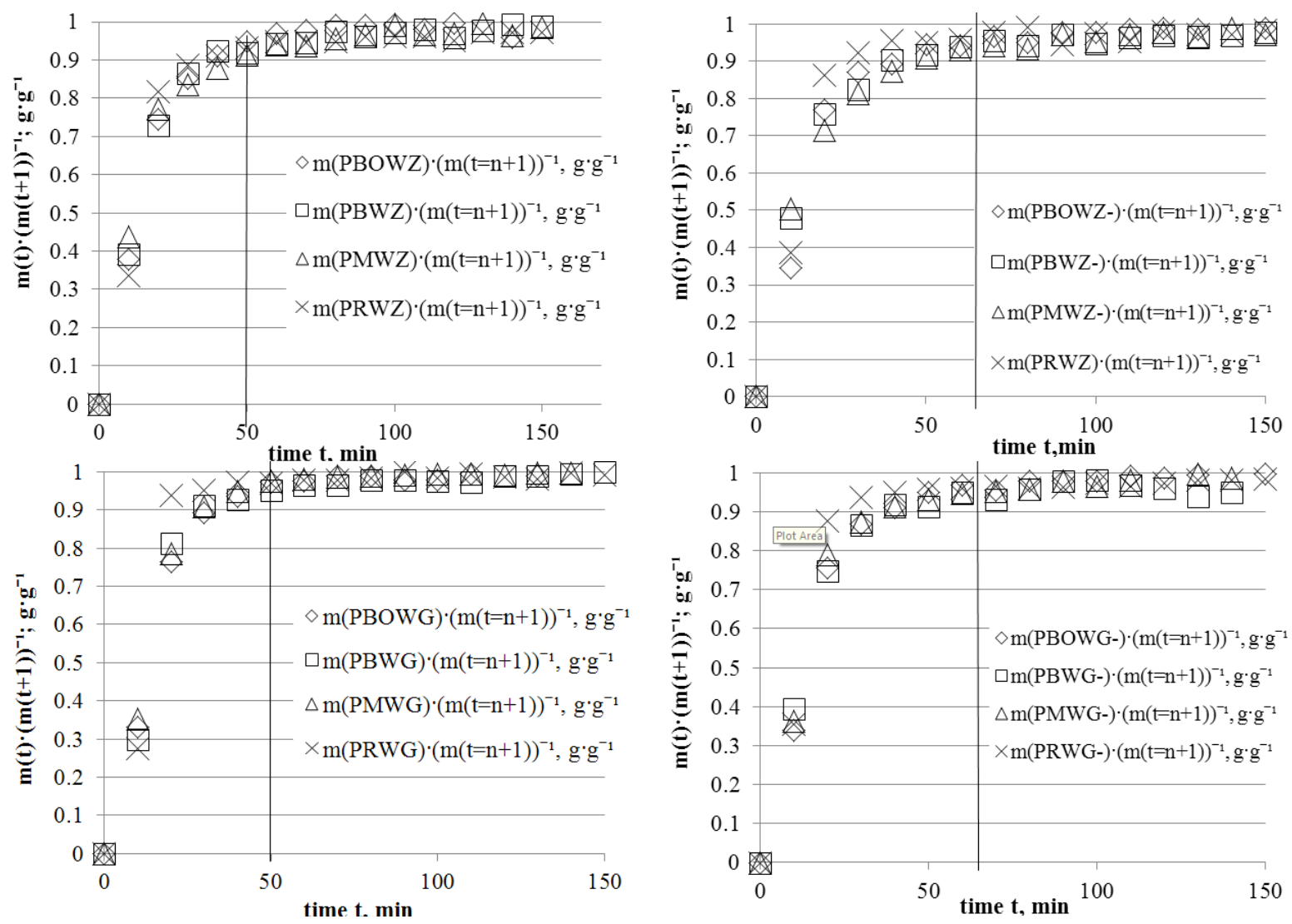

Fig.5. Stabilization of relative mass gain of dried Idared apple (slices) during rehydration: $\mathrm{a}$ - in distilled water at $20.0 \pm 1.0^{\circ} \mathrm{C}$ - material in a convection dryer with circulation; $\mathrm{b}$ - in distilled water at $20.0 \pm 1.0^{\circ} \mathrm{C}$ - material obtained in a convection oven without circulation; $\mathrm{c}$ - in distilled water at

$95.0 \pm 5.0^{\circ} \mathrm{C}-$ materialobtained in a convection dryer with circulation; $\mathrm{d}-$ in distilled water at $95.0 \pm 5.0^{\circ} \mathrm{C}-$ material in a convection dryer without circulation. Source: own study. The legend:

dried sample with air circulation

$\mathrm{m}(\mathrm{PBOWZ}) \cdot(\mathrm{m}(\mathrm{t}=\mathrm{n}+1))^{-1} \mathrm{~g} \cdot \mathrm{g}^{-1}-$ relative weight gain of the rehydrate - cold water without pre-treatment,

$\mathrm{m}(\mathrm{PBWZ}) \cdot(\mathrm{m} \quad(\mathrm{t}=\mathrm{n}+1))^{-1} \mathrm{~g} \cdot \mathrm{g}^{-1}$ - relative weight gain of rehydrate - cold water blanching,

$\mathrm{m} \quad(\mathrm{PMWZ}) \cdot(\mathrm{m} \quad(\mathrm{t}=\mathrm{n}+1))^{-1} \mathrm{~g} \cdot \mathrm{g}^{-1}$ - relative weight gain of the rehydrate - cold water microwave drying,

$\mathrm{m}(\mathrm{PRWZ}) \cdot(\mathrm{m} \quad(\mathrm{t}=\mathrm{n}+1))^{-1} \mathrm{~g} \cdot \mathrm{g}^{-1}-$ relative weight gain of the rehydrate - cold water osmotic drying.

$\mathrm{m}(\mathrm{PBOWG}) \cdot(\mathrm{m}(\mathrm{t}=\mathrm{n}+1))^{-1} \mathrm{~g} \cdot \mathrm{g}^{-1}-$ relative weight gain of the hot water rehydrate - without pre-treatment,

$\mathrm{m}(\mathrm{PBWG}) \cdot(\mathrm{m} \quad(\mathrm{t}=\mathrm{n}+1))^{-1} \mathrm{~g} \cdot \mathrm{g}^{-1}-$ relative weight increase of rehydrate hot water blanching,

$\mathrm{m}(\mathrm{PMWG}) \cdot(\mathrm{m} \quad(\mathrm{t}=\mathrm{n}+1))^{-1} \mathrm{~g} \cdot \mathrm{g}^{-1}$ - relative weight increase of rehydrate hot water microwave drying,

$\mathrm{m}(\mathrm{PRWG}) \cdot(\mathrm{m} \quad(\mathrm{t}=\mathrm{n}+1))^{-1} \mathrm{~g} \cdot \mathrm{g}^{-1}-$ relative weight increase of rehydrate hot water - osmotic drying dried samples without air circulation

$\mathrm{m}(\mathrm{PBOWZ}) \cdot(\mathrm{m}(\mathrm{t}=\mathrm{n}+1))^{-1} \mathrm{~g} \cdot \mathrm{g}^{-1}-$ relative weight gain of the rehydrate - cold water without pre-treatment,

$\mathrm{m}(\mathrm{PBWZ}-) \cdot(\mathrm{m} \quad(\mathrm{t}=\mathrm{n}+1))^{-1} \mathrm{~g} \cdot \mathrm{g}^{-1}-$ relative mass gain of rehydrate - cold water - blanching, $\mathrm{m}\left(\right.$ PMWZ-) $\cdot(\mathrm{m}(\mathrm{t}=\mathrm{n}+1))^{-1} \mathrm{~g} \cdot \mathrm{g}^{-1}$ - relative weight gain of the rehydrate - cold water microwave drying,

$\mathrm{m}(\mathrm{PRWZ}-) \cdot(\mathrm{m} \quad(\mathrm{t}=\mathrm{n}+1))^{-1} \mathrm{~g} \cdot \mathrm{g}^{-1}$ - relative weight gain of the rehydrate - cold water osmotic drying.

$\mathrm{m}($ PBOWG- $) \cdot(m(t=n+1))^{-1} \mathrm{~g} \cdot \mathrm{g}^{-1}-$ relative weight gain of the rehydrate - hot water without pre-treatment,

$\mathrm{m}(\mathrm{PBWG}-) \cdot(\mathrm{m}(\mathrm{t}=\mathrm{n}+1))^{-1} \mathrm{~g} \cdot \mathrm{g}^{-1}$ - relative weight increase of rehydrate hot water blanching,

$\mathrm{m}\left(\mathrm{PMWG}^{-}\right) \cdot(\mathrm{m}(\mathrm{t}=\mathrm{n}+1))^{-1} \mathrm{~g} \cdot \mathrm{g}^{-1}-$ relative weight gain of rehydrate - hot water microwave drying,

$\mathrm{m}($ PRWG- $) \cdot(\mathrm{m}(\mathrm{t}=\mathrm{n}+1))^{-1} \mathrm{~g} \cdot \mathrm{g}^{-1}$ - relative weight gain of rehydrate - hot water - osmotic drying 


\section{Summary}

The method of the pretreatment has no significant effect on the mass gain of the sample during rehydration at low temperature, with the exception of the osmotic drying with forced convection. Preparation drying in a convection oven without circulation of the drying medium has a significant effect on the rehydration process, especially at high temperatures. Rehydration in water at $95.0 \pm 5.0^{\circ} \mathrm{C}$ showed the lowest degree of rehydration of the samples, regardless of the pretreatment of the material. Water removal without phase transformation in the process of osmotic drying, using a solution of the starch, caused the reduction in the efficiency of rehydration by $42 \%$ percent.This can facilitate the storage of dried apple slices obtained by convection drying and in turn, the preservation of food. For high-temperature rehydration, the lowest mass gains were observed for all samples dried by convection without forced circulation of drying medium, regardless of the processes of the first stage. In the process of low-temperature hydration the samples blanched and dried by forced convection had the highest susceptibility to rehydration.

\section{Acknowledgments}

This research was financed by the Ministry of Science and Higher Education of the Republic of Poland

\section{References}

[1] Zielińska M., Markowski M. The influence of microwave-assisted drying techniques on the rehydration behavior of blueberries (Vacciniumcorymbosum L.). Food chemistry, 196, 2016, pp. 1188-1196.

[2] Doymaz İ. Effect of citric acid and blanching pre-treatments on drying and rehydration of Amasya red apples. Food and Bioproducts Processing, 88(2-3), 2010, pp. 124-132.

[3] Maskan M. Drying, shrinkage and rehydration characteristics of kiwifruits during hot air and microwave drying. Journal of food engineering, 48(2), 2001, pp. 177-182.

[4] Ciurzyńska A., Lenart A. Rehydration and sorption properties of osmotically pretreated freezedried strawberries. Journal of Food Engineering, 97(2), 2010, pp. 267-274.

[5] McMinn W. A. M., Magee T. R. A. Physical characteristics of dehydrated potatoes-Part I. Journal of Food Engineering, 33(1-2), 1997a, pp. 37-48.

[6] Krokida M. K., Kiranoudis C. T., Maroulis, Z. B. Viscoelastic behaviour of dehydrated products during rehydration. Journal of Food Engineering, 40(4), 1999, pp. 269-277.

[7] Lewicki P. P. Some remarks on rehydration of dried foods. Journal of Food Engineering, 36(1), 1998, pp. 81-87.

[8] McMinn W. A. M., Magee T. R. A.. Physical characteristics of dehydrated potatoes-Part II. Journal of Food Engineering, 33(1-2), 1997b, pp. 49-55.

[9] Jayaraman K. S., Gupta D. D., Rao N. B. Effect of pretreatment with salt and sucrose on the quality and stability of dehydrated cauliflower. International journal of food science \&technology, 25(1), 1990, pp. 47-60. 